\title{
La enseñanza de la historia reciente y la formación moral. Dilemas de un vínculo imprescindible
}

\author{
Teaching Recent History and Moral Training. \\ Dilemmas of an Essential Link
}

Diego H. Arias Gómez ${ }^{1}$

\section{Resumen}

El presente artículo busca profundizar en la relación entre la enseñanza de la historia reciente en Colombia y la formación moral. Para tal efecto conceptualiza inicialmente sobre historia reciente, sobre su enseñanza y sobre la formación moral. Además se exponen algunos resultados de un estudio situado con jóvenes que pone en evidencia la configuración moral como filtro para el aprendizaje de la historia en la escuela, especialmente la relacionada con la violencia de las últimas décadas.

Palabras clave

Enseñanza de las ciencias sociales, formación ética y moral, enseñanza de la historia reciente.

\section{Abstract}

This article seeks to analyze the relationship between teaching recent history and moral training in Colombia. For this purpose recent history, teaching and moral training are first conceptualized. Furthermore, some results from a study based on the youth are showed which proves that moral configuration works as a filter in learning history at school, particularly as it relates to violence in recent decades.

Key words

Teaching social sciences, ethical and moral training, teaching recent history.

Artículo recibido el 17 de octubre de 2014 y aprobado el 7 de abril de 2015

1 Universidad Distrital Francisco José de Caldas, Bogotá, Colombia. Grupo de investigación Amautas. Correo electrónico: diegoarias8@gmail.com 
Yo dicto sociales pero yo no dicto tanta geografía ni tanta historia, ya nada de curvas, ni nada de memoria, no, yo lo que más les inculco a los muchachos son valores: responsabilidad, respeto, la letra, la ortografía, el comportamiento. No me importa tanto que los muchachos sepan de la China, de India, lo más elemental que les pueda dar, pero lo que más, ellos me han escrito en estos días de recuperación que están muy agradecidos porque han aprendido a ser responsables.

(Testimonio de la profesora Teresa, citado en

García, 2002, p. 45)

\section{Introducción}

En los últimos lustros se ha instalado en la literatura educativa y de las ciencias sociales el concepto de enseñanza de la historia reciente/presente o del pasado reciente para referirse a los fenómenos de no lejana sucesión que han afectado la dinámica de las sociedades, en especial latinoamericanas. En otros contextos se habla de enseñanza de cuestiones socialmente vivas (Pagés y Santisteban, 2013) o de enseñanza de aspectos históricamente relevantes (Falaize, 2010). Aparte del nombre que se les otorgue, un ingrediente clave en la mirada de estos acontecimientos está relacionado con las opciones ético-políticas que los sujetos contemplan cuando seleccionan los contenidos del pasado a enseñar (Carretero, 2005). Se trata del filtro de los esquemas morales del docente en la elección de los acontecimientos y eventos que imparte en su aula.

Los análisis sobre el pasado reciente no han estado exentos de debate y divergencia, ello se explica, en parte, por las diferencias en los propósitos en su elaboración y por el eventual público receptor. El estudio de acontecimientos históricos de reciente ocurrencia ha ocasionado múltiples lecturas y reacciones, que en no pocas oportunidades han impedido diálogos abiertos y reflexión sobre las fuentes, lo mismo que su impacto en la población interesada en tales reflexiones.

La mirada sobre eventos sucedidos recientemente, además del rigor científico en la captura de información, implica la explicitación de las posiciones ético-políticas y morales, pues los discursos sobre la verdad histórica se revelan como interesados y subjetivos, aunque los enunciados lo oculten. Además su producción y divulgación despliega reflexiones sobre la realidad actual y, en muchos casos, invita a los ciudadanos comunes a acentuar o modificar apuestas éticas que se articulan con opciones personales en pro de la transformación o la perpetuación de la estructura social. Es decir, el examen de la historia reciente interesa porque no solo se refiere al pasado, sino que dice algo respecto al presente, sus conflictos y sus protagonistas.

En tal sentido, son ilustradoras las múltiples reacciones que ha ocasionado el informe sobre el conflicto colombiano elaborado por el Grupo Memoria Histórica (2013), que reconstruyó la memoria de la violencia de las últimas décadas del país en un amplio y documentado texto; o la creación posterior de la Comisión de la Verdad Histórica constituida en el marco de los diálogos de paz entre la insurgencia y el Estado colombiano, conformada, a petición de las partes, por intelectuales y académicos de distinta orientación ideológica, y que tiene la misión de redactar un nueva versión de los hechos y situaciones de violencia de las últimas décadas. Sobre este último grupo escribió un columnista:

Evidentemente, tal comisión, por más de que esté integrada por esas eminencias, no podrá redactar un documento nuevo, coherente, "neutro" y "pluralista". La tarea que les han impuesto puede ser otra: "construir un relato", como detallaron los jefes de las Farc en Cuba, es decir servir un refrito del cuestionado estudio lanzado el año pasado por la comisión presidida por Gonzalo Sánchez, profesor de la Universidad Nacional. [...] El texto de la "comisión histórica" tendrá, pues, un marco teórico contrario a la verdad. Tendrá que decir lo que siempre dijo el Partido Comunista Colombiano. (Mackenzie, 2014, s.p.)

Para el periodista que escribió la anterior nota, más allá del rigor académico que se imponga en la conformación y en las tesis que resulten de las investigaciones de las comisiones, existe un interés soterrado. Mackenzie denota un prejuicio que descali- 
fica los resultados de esos intelectuales pues, según él, persiste un marco teórico contrario a la verdad y finalmente dirán lo que otros quieren que digan. ¿Cuál será la verdad de su verdad?

A tono con el sentido de las anteriores ideas, el contenido del presente escrito busca profundizar en la relación entre la enseñanza de la historia reciente en Colombia y las reflexiones éticas y morales a partir de algunos hallazgos de un estudio situado. ${ }^{2}$ Para tal efecto, se presentarán inicialmente los insumos teóricos referidos a la enseñanza de la historia reciente, su desarrollo en Colombia y conceptualizaciones sobre la formación moral y ética; luego se expondrá el cruce de estas dos temáticas para, finalmente, presentar algunos resultados de acuerdo a la información empírica proporcionada por estudiantes que participaron de la investigación.

\section{La enseñanza de la historia reciente}

La categoría historia reciente se impuso fundamentalmente en el siglo pasado después de la Segunda Guerra Mundial y de las dinámicas generadas luego de los procesos de descolonización. Su utilización parte de la necesidad social de retomar la comprensión de los fenómenos traumáticos que sucedieron, sobre todo a raíz de los conflictos sociales y bélicos, y de las versiones que a través de los años se transmitieron sobre las relaciones entre vencedores y vencidos, sobre todo las que buscaron reivindicar el lugar de las víctimas. La presencia de las víctimas de los diferentes conflictos se articula con la importancia que en la década de los ochenta adquirieron los discursos sobre la memoria (Huyssen, 2002), impulsados por los medios de comunicación de masas al calor del debate sobre el Holocausto y la conmemoración de distintos aniversarios que evocaban acontecimientos de carácter nefasto para algunos pueblos europeos.

2 Apartes de la investigación doctoral titulada "Identificación con la nación propia en jóvenes universitarios, maestros en formación. Imaginarios sociales de nación y escuela", realizada por el autor bajo la dirección del Dr. Alexander Ruiz del Doctorado Interinstitucional en Educación de la Universidad Pedagógica Nacional.
Para Traverso (2000), el pasado se transforma en memoria luego de que haya sido tamizado según las sensibilidades culturales, las tensiones éticas y los intereses políticos del presente. Así, el autor recalca la versión intencionada con que los discursos del presente elaboran los relatos sobre la historia. Por ello, es importante la "invención de la tradición", al decir de Hobsbawm, que se factura desde la escuela, y que consiste en un grupo de prácticas,

Normalmente gobernadas por reglas aceptadas abierta o tácitamente y de naturaleza simbólica o ritual, que buscan inculcar determinados valores o normas de comportamiento por medio de su repetición, lo cual implica automáticamente continuidad con el pasado. De hecho, cuando es posible, normalmente intentan conectarse con un pasado histórico que les sea adecuado. (Hobsbawm, 1983, p. 8)

En este contexto, las distintas versiones sobre la historia reciente, incluidas sus modalidades escolares, sufren un permanente conflicto por imponer una narrativa legítima y presentable del pasado nacional.

Para la realidad latinoamericana, los estudios sobre la historia reciente y sobre la memoria emergen como categorías analíticas en medio del proceso de transición democrática en las naciones que padecieron regímenes dictatoriales, en cuanto estrategia social de recomposición y reconstrucción del tejido social fracturado, a la vez que bandera por la defensa de los derechos humanos, el derecho a la verdad sobre los crímenes cometidos y como contenido común de organización de la sociedad civil (Dussel, 2002; Jelin, 2003).

Para Franco y Levín (2007), más que partir de reglas temporales, el recorte del pasado reciente se hace asumiendo criterios subjetivos y variables que modifican la visión de este pasado sobre la base de problemas contemporáneos. Tal principio pone en evidencia la importancia de las apuestas ético-políticas, pues ellas interfieren notablemente en los contenidos de la historia reciente. Al tenor de nuevos hallazgos e inéditas interpretaciones de acontecimientos pasados, sensibles para la socie- 
dad, los recortes sobre la significancia del tiempo se mueven en función de lo que se quiere demostrar. No hay límites precisos. Grupos, organizaciones y Estado con frecuencia debaten respecto a las fechas que competen a las comisiones de la verdad, a las investigaciones judiciales o para definir reparaciones a las víctimas de guerras. En este asunto se juega la legitimidad de unas luchas durante mucho tiempo acalladas por los medios oficiales, pero también la visibilidad de ciertos actores, la definición de juicios a culpables y las responsabilidades morales y legales, junto a la no menos importante designación de presupuesto oficial para tal empresa.

Según Fazio (2007), los avances historiográficos, la procura de novedad y la necesidad de responder a ciertas expectativas sociales explican parte de la emergencia del campo de la historia del tiempo presente en los últimos años. Para este autor, tales dinámicas son impulsadas, en los noventa, por la caída del muro de Berlín y los procesos de globalización. De igual manera, los cambios económicos y tecnológicos desplazaron el tiempo de la política como eje estructurante por el de la economía y el mercado, desvinculando el presente del pasado y transformando todo en presente, en inmediatez. Así las cosas, la historia del tiempo presente,

Al tiempo que es una perspectiva de análisis de lo inmediato, también debe considerarse como un periodo [...] La historia del tiempo presente no sólo es una inquietud de los historiadores, sino una necesidad social que nos debe permitir entender las fuerzas profundas que están definiendo nuestro abigarrado presente. (Fazio, 2007, p. 51)

Sin embargo, para Jelin (2003), más allá de la moda o el clima de la época, el tema de la recuperación de dichos eventos se torna trascendental para la sociedad cuando se articulan a hechos traumáticos de carácter político, a eventos de represión oficial y a situaciones de dolor colectivo.

Hoy, en forma creciente, acontecimientos de reciente detonación han venido preocupando la agenda pública y la labor de historiadores en una disputa territorial con otros cientistas sociales, "asunto que no ha estado exento de debates de carácter disciplinar respecto a quién corresponde este recorte temporal de lo social" (Herrera, 2009, p. 13). Tal debate gradualmente se ha traslado también a la enseñanza de las ciencias sociales y la historia, cuyo interés en elementos de la realidad reciente agudiza la polémica en cuanto que dichos acontecimientos hacen parte de la memoria por su carácter político y por su vigencia. No solo muchos de los protagonistas de estos eventos no han muerto, sino que están vivos en las memorias de grupos y comunidades que consideran que hay muertos sin identificar, crímenes impunes, victimarios sin juzgar y otras historias por contar. En suma, hablar de historia reciente es mencionar un pasado que por diferentes circunstancias se resiste a pasar.

En América Latina, la experiencia de las dictaduras en el Cono Sur vitalizó la necesidad de plantear una lucha por la construcción de los significados de hechos del pasado desde la escuela (Jelin y Lorenz, 2004; Funes, 2006; Higuera, 2012). Aquí, la enseñanza de la historia asumió el estudio del pasado reciente como una lucha política por cuestionar verdades oficiales y visibilizar versiones subalternas por algún tiempo desconocidas. Además, el estudio de la historia reciente buscó propiciar en las nuevas generaciones posicionamientos morales y ético-políticos frente a conflictos pretéritos y presentes de grupos y fuerzas alternativas que chocaron contra el poder hegemónico, es decir, la enseñanza de la historia reciente se utilizó en algunos contextos como campo estratégico de formación política escolar. Para Kriger (2011):

La escuela debe asumir con más fuerza el desafío de construir una comprensión histórica del pasado reciente, que pueda configurarse como una herramienta para la construcción política del presente y proyección del futuro [...]. En otras palabras se trata de promover la conciencia histórica [...] y el pensamiento político en una sociedad que ha superado, con grandes tensiones y conflictos aún no resueltos, el desafío de desandar la amnesia y la impunidad. La escuela allí tiene una importante tarea. (p. 49) 
Aunque tal incorporación al currículo de la historia reciente no ha estado exenta de problemas e incongruencias (De Amézola, 2008), su impacto se ha sentido en muchos países del continente, golpeados por graves conflictos sociopolíticos de trascendencia nacional e internacional. La escuela y la enseñanza de lo histórico son interpeladas por impactantes fenómenos de la historia reciente de alta sensibilidad social.

La intromisión incómoda del pasado cercano en la escuela dramatiza con fuerza el carácter no neutral que siempre han tenido los contenidos de la enseñanza de lo histórico-social (Arias, 2005), y que ahora, a propósito de hechos polémicos y dolorosos para la sociedad, tiene un importante papel para que tales acontecimientos nunca se repitan. Para Levín (2007), no basta con repudiar ciertos hechos, no es suficiente repetir fórmulas de conjuro contra un pasado ominoso ("nunca más", "basta ya"), más bien, dice la autora,

El desafío es acompañar a los estudiantes en la construcción de una perspectiva crítica que les permita comprender por qué sucedió lo que pasó, comprender qué rasgos, qué características [...] posibilitaron que ocurriera lo que ocurrió y comprender, asimismo, por qué ese pasado ha sido recordado de los modos en que ha sido recordado. (Levín, 2007, p. 177)

Según Kriger (2011), la tradicional misión de la escuela que enfrenta lo cognitivo y lo identitario se tensiona aún más con la enseñanza del pasado reciente y pone en evidencia la importancia del papel de la memoria en las actuales sociedades, especialmente las que han pasado o están tramitando pasados traumáticos. En esta línea, los contenidos y orientaciones de este pasado incorporado en la escuela son polémicos, conflictivos y, sobre todo, objeto de disputa por diferencias agencias sociales. ¿Quién define lo que debe ser enseñado en la escuela respecto a las últimas décadas?, ¿con qué insumos cuentan los docentes para interpretar el pasado reciente que llevan al aula?, y, aún más, ¿qué contenidos privilegian enseñar de los últimos tiempos y por qué? Son algunas preguntas que vale la pena formularse respecto a esta realidad y sus posibilidades de enseñanza. Para Jelin (2003), nos encontramos en una lucha por las representaciones del pasado, y estas luchas implican, por parte de diferentes actores,

Estrategias para "oficializar" o "institucionalizar" una (su) narrativa del pasado. Lograr posiciones de autoridad, o lograr que quienes las ocupan acepten y hagan propia la narrativa que se intenta difundir, es parte de estas luchas. También implica una estrategia para "ganar adeptos", ampliar el círculo que acepta y legitima una narrativa, que la incorpora como propia, identificándose con ella. (p. 40)

Los pasados traumáticos que se resisten a pasar, incomodan al presente, son problemáticos para la sociedad y para el tipo de escuela que cuestiona las versiones oficiales, consignadas en los libros de texto, en plataformas virtuales del Estado o en lineamientos curriculares, mayormente, cuando este pasado pone en entredicho la legitimidad misma del Estado (Carretero y Borrelli, 2010). La enseñanza de la historia reciente, con frecuencia, puede molestar a la institucionalidad y a grupos de poder ligados a ella que han cohonestado con hechos que violan los derechos fundamentales de personas y comunidades y que, adicionalmente, han impuesto traducciones $\mathrm{y}$ versiones acomodadas sobre lo sucedido con los influyentes medios que tienen a su disposición.

Para Carretero y Borrelli (2010), la importancia de la enseñanza del pasado reciente, en cuanto proyecto, irrumpe por la confluencia de varios factores: la búsqueda de elementos que refuercen la identidad propia, la mirada sobre conflictos del pasado con miras empresas futuras, la exigencia de historias más objetivas y menos míticas, y la comparación de versiones de la historia alternativas de un mismo pasado.

En suma, la enseñanza de la historia reciente tensiona la lógica de las tradicionales disciplinas escolares ocupadas del abordaje histórico y social, a la vez que conflictúa la escuela al incorporar unos contenidos problemáticos y complejos ligados a sucesos de reciente ocurrencia, que desafían los 
currículos prescritos y que, como se verá, cuestionan los órdenes morales de la sociedad y de la comunidad escolar en particular.

\section{Enseñanza de la historia reciente en Colombia}

Según Herrera (2009), pese a la antigüedad de los estudios sobre la historia reciente en el mundo, subsisten algunas problemáticas inconclusas sobre este campo para las ciencias sociales, tales como la periodización de los fenómenos objeto de análisis, las fuentes legítimas de información, las áreas disciplinares pertinentes para su abordaje y, finalmente, los límites y alcances de sus reflexiones. Para la autora, las llaves de lectura referida al pasado reciente son la experiencia vivida y la memoria, en el sentido que - evocando a Koselleck - el vínculo del pasado con el presente y el futuro se articulan en una red de sentido. Acogiendo esta conceptualización, la literatura sobre la enseñanza de la historia reciente en Colombia, de escasa producción, ha estado centrada en la reflexión sobre la violencia política en el país, especialmente de mediados del siglo xx en adelante.

$\mathrm{Al}$ respecto, Rodríguez (2012) da contenido a la categoría historia reciente bajo el supuesto de sistematizar trabajos de grado que estudiaron el conflicto armado colombiano para auscultar las relaciones entre memoria y enseñanza de la historia reciente en el ámbito de formación de profesores. Según la autora, la enseñanza de la historia reciente materializa los cruces entre la memoria social y la formación política en la escuela, en tal sentido:

La decisión de incorporar en el currículo de ciencias sociales temáticas relacionadas con el conflicto armado, afecta las relaciones escuelacomunidad, amplía y complejiza los contenidos de la enseñanza y contribuye a la reelaboración de la memoria social de los jóvenes escolares. (Rodríguez, 2012, p. 170)

Por su lado, Herrera, Ortega, Cristancho y Olaya (2013), en un sugestivo cruce de la enseñanza de la historia reciente con la pedagogía de la memoria, señalan que, a diferencia de otros países de la región, en Colombia no se han dado políticas educativas sistemáticas que prevean el trabajo en el aula de la enseñanza de la historia reciente. A falta de programas estatales, más bien, se han dado importantes iniciativas informales desde organizaciones no gubernamentales y, sobre todo, de grupos organizados de la sociedad civil, especialmente de víctimas y de derechos humanos. Para los autores, la enseñanza de la historia reciente, en cuanto categoría que explica la pedagogía del conflicto interno, ha circulado gracias al accionar de los movimientos sociales y la educación popular.

Pensando en propuestas, Herrera y Merchán (2012) postulan que la enseñanza de la historia reciente en Colombia ha de incluir narrativas que den cuenta de las prácticas de terror impuestas desde agentes del Estado, sobre todo teniendo en cuenta que el país no ha migrado hacia procesos de transición luego de dictaduras, como en otros contextos, ni han cesado las manifestaciones del largo conflicto social y armado que se padece. Para las autoras:

La guerra sucia, el terrorismo de Estado y la multiplicidad de actores del conflicto, han puesto en entredicho las características democráticas de las instituciones y sus dificultades para la tramitación de la violencia, así como las formas corrientes de comprensión de estos fenómenos por parte de la sociedad. (Herrera y Merchán, 2012, p. 148)

Por ello, afirman, es pertinente el trabajo pedagógico con narrativas testimoniales, que han impulsado fundamentalmente organizaciones de la sociedad civil, y cuya tramitación en la escuela se convierte en una importante invitación a realizar.

Por su lado, en sintonía con los estudios de la memoria, Aponte (2012) considera que buena parte de las versiones escolares cuyo interés estuvo en la época de la violencia, lejos de ofrecer miradas amplias, han reproducido la memoria oficial, lo que ha devenido en la exclusión de otros relatos sobre el fenómeno. La investigación del autor denota un conjunto de discursos docentes sobre el pasado reciente que se preocupa básicamente por el desarrollo de un componente axiológico en el que la focalización sobre la violencia del pasado se hace procurando transmitir en los estudiantes sen- 
timientos para que eviten los conflictos y propendan por una visión edulcorada de la paz; de manera que, dice el autor, "las representaciones del pasado, lejos de constituirse en herramientas para el análisis estructural de la realidad circundante de manera crítica, se conviertan en elementos que normalizan a los sujetos, haciendo ver el conflicto como algo indeseable" (p. 160).

\section{Enseñanza de la historia reciente filtrada por las opciones éticas y morales}

El tema de la configuración moral reviste una crucial importancia en el campo educativo, en la medida que se descubre que las opciones morales y éticas, provenientes de un sinnúmero de aprendizajes, contribuyen a perfilar el comportamiento y el acceso a los sabes dentro y fuera de la escuela. Hoy es posible pensar que el estudiante construye parte de las representaciones frente al mundo que le rodea a partir de la educación moral que asimila, máxime cuando se le asigna al sujeto actual la responsabilidad de hacerse cargo de sí, al tiempo que problemas estructurales son presentados como inconvenientes personales (Bauman, 2001).

La concepción de ética o de moral aquí trabajada se define como el esquema no consciente del mundo que define los pensamientos y las prácticas individuales, y que, al decir de Taylor (2004):

No se limita al conocimiento y aceptación de una serie de normas, sino que añade el reconocimiento de una serie de rasgos del mundo [...] que hacen que ciertas normas sean a un tiempo buenas y [...] realizables. En otras palabras, la imagen de orden moral no solo supone una definición de lo que es justo, sino también del contexto que da sentido a luchar por ello y esperar su realización. (p. 21)

Las decisiones morales no solo determinan las acciones de las personas, sino que usualmente no se cuestionan ni se reconoce el proceso mediante el cual condicionan las concepciones propias del mundo. Los órdenes morales ofrecen, para cada persona, los esquemas de clasificación, organización y jerarquización del entorno, así que comportan las discriminaciones que se tienen sobre lo que es correcto y lo que es errado, lo mejor o lo peor, lo bueno y lo malo (Taylor, 1989). Para Taylor, la moral no solo se refiere al trato que, se considera, debe dársele a los otros, también toca lo concerniente a la vida personal que merece ser vivida, la vida buena, y a la noción de dignidad. La moral, en suma, ofrece el marco referencial que da sentido a la propia existencia, además ubica y valora el sentido de la vida de los otros en términos de adecuación a dicho marco. Los esquemas morales son históricos, o sea, cambian con el tiempo en cuanto que dependen de los poderes que tienen la fuerza para definir lo que es bueno, deseable y bello. He aquí un interesante ejemplo histórico que el autor trae a colación de lo que en cierto momento fue catalogado como vida buena:

La vida del ciudadano, del guerrero o del ciudadano soldado se tiene en más alta estima que la existencia simplemente privada, dedicada al arte de la paz y al bienestar económico. La vida mejor va marcada por una aureola de fama y gloria que presta, o al menos señala, a quienes triunfan en ella con brillantez. Estar en la vida pública o ser un guerrero es ser, por lo menos, candidato a la fama. Estar dispuesto a poner en peligro la tranquilidad, la riqueza, incluso la propia vida, en aras de la gloria es la marca de un verdadero hombre; y a quienes no se atreven a ello se les juzga despectivamente como "afeminados". (Taylor, 1989, p. 35)

El anterior modelo pone de manifiesto que las creencias sociales sobre la vida buena marcan las opciones personales y definen el marco de las interacciones sociales, además denota la importancia del componente social e histórico de los sistemas morales, que se modifican con las épocas pero que tienen la fuerza para organizar la vida y la muerte de muchas personas.

Para efectos de articular las anteriores ideas con la dinámica escolar, es clave comprender que los esquemas morales no dan su impronta en la relación del sujeto con la realidad, sino que marcan su estructura cognitiva, esto es, su relación con el saber y el conocimiento (Carretero, 2005), que es parte de la realidad, y, por supuesto, en el acceso a las versiones de la historia reciente de su nación (Ruiz, 2011; 
Arias y Ruiz, 2013). Por ejemplo, las narrativas sobre la nación esencialista y romántica, predestinada a existir desde tiempos inmemoriales y con vocación de triunfo, que con frecuencia relatan entusiasmados algunos escolares, informa más de apuestas morales - aprendidas o no en la escuela- preocupadas de recabar en el pasado espíritus de grandeza, que de rigor histórico respecto a lo que sucedió en su nación. Esto quiere decir que casi siempre los marcos de referencia morales adaptan y le dan forma (de-forman) a los acontecimientos del pasado para que se ajusten a las valoraciones del tiempo presente que se tienen.

Para Carretero (2005), existe una fuerte relación entre los juicios morales y las posibilidades del aprendizaje cognitivo y de cambio conceptual que el abordaje de la enseñanza de la historia y las ciencias sociales implica. En otras palabras, según el autor, el aprendizaje del conocimiento social e histórico está fuertemente condicionado por los valores de los sujetos que se acercan a este saber. Evocando un estudio en el que ciertas personas eran interpeladas en sus prejuicios sobre el pasado reciente a partir de información fidedigna, Carretero concluye que "los humanos manejamos la información de tal manera que no solo somos reacios a cambiar nuestras ideas y actitudes sobre los fenómenos sociales, sino que incluso solemos deformar la información con tal de mantener nuestras posiciones" (2005, p. 23).

Esta situación, indagada por el autor, es relevante para entender los conceptos y la metodología respecto al abordaje pedagógico de la historia reciente en Colombia, es decir que sin la comprensión, análisis y autoconciencia de los esquemas morales que los docentes y estudiantes presentan, será muy difícil emprender estrategias didácticas que contribuyan a una comprensión compleja y dinámica de la realidad de las últimas décadas de la nación. Sentirse conmiserablemente víctima, denostar pasionalmente sobre algunas clases sociales, resaltar exclusivamente el legado trágico o valorar el pasado como un campo donde solo se debaten vencedores y vencidos, conduce a lecturas históricas binarias y dicotómicas que reducen la complejidad de los hechos.
En este sentido, una investigación sobre el pasado reciente en Colombia pudo constatar la profunda relación que se da entre apuestas morales y versiones acomodadas del pasado nacional (Arias, 2014). ${ }^{3}$ En ella se les preguntó a un grupo de estudiantes recién ingresados a la universidad, futuros docentes de ciencias sociales, qué contenidos privilegiarían enseñar en el hipotético caso de que ya fueran profesionales en ejercicio. El objetivo fue recabar en los imaginarios sociales que tenían sobre la historia reciente de su nación. La consigna fue escribir un pequeño relato sobre los hechos, situaciones o ideas de las últimas décadas que desearían enseñar a sus alumnos. Como hallazgo clave se encontró que la mayoría de los jóvenes participantes dieron cuenta de relatos episódicos, fragmentados y mayoritariamente organizados en orden cronológico.

Más allá de las particularidades y del hecho de que la violencia ocupó un lugar bastante destacado en los relatos, fue evidente el fuerte contenido moral de sus construcciones narrativas. Resaltó la tendencia a ubicar culpables, héroes y villanos, además se destacaron juicios tajantes y afirmaciones con gran carga emotiva. Veamos una selección de tres fragmentos:

Relato 1:

Yo le hablaría a mis estudiantes sobre el suceso de toma y retoma del Palacio de (in)justicia porque creo que todo colombiano debe de conocer y llenarse de indignación sobre los hechos ocurridos ese día. Creo que esa es una de las marcas más grandes que tiene este país, se me pone la piel de gallina al leer o ver información sobre este hecho y eso se lo quiero transmitir a los estudiantes, que

3 La investigación fue de orden cualitativo, la estrategia utilizada se centró en el uso relatos biográficos o relatos de vida (orales, visuales y escritos). Como técnicas se aplicaron la entrevista en profundidad, grupos focales y la producción de un escrito. Se realizaron 17 entrevistas, 2 grupos focales, 71 relatos escritos y 114 fotografías o relatos visuales. El análisis de contenido fue la técnica seleccionada para organizar, clasificar y jerarquizar los datos. Los resultados aquí presentados corresponden a parte de uno de los objetivos específicos y solo al trabajo con estudiantes de primer semestre. Vale aclarar que los relatos escogidos en el presente artículo corresponden a una muestra que ilustra la tesis que quiere ser demostrada. Otros matices y otros hallazgos pueden ser consultados en el texto original. 
analicemos qué odio y resentimiento, qué tan enfermas se encuentran nuestras fuerzas armadas (y en general todo el país) para reaccionar a estos hechos como reaccionaron, y además cuáles fueron las causas y qué tan reales y válidas fueron para que el M-19 decidieran tomarse el Palacio.

Además los contextualizaría sobre lo que pasaba en el país en este tiempo, como la vida de todos tomó precio y perdió valor, vivir se volvió un milagro (y si no se cree en milagros hay que preguntarle a los padres cómo hicieron para sobrevivir) porque el riesgo era inminente a toda hora; el país estaba en guerra con todo el mundo, Locombia se dividió en bandos, no en dos sino en muchos, lo que hizo la violencia más aguda. Todo era claro, nada era seguro, las ciudades y los campos se volvieron campos de guerra, lo mejor que le podía pasar a alguien era morir, la muerte natural se volvió un lujo que ni los ricos a veces podían conseguir.

Me gustaría estudiar con mis estudiantes todos los desaparecidos, ver sus fotos y descubrir su nombres, escuchar sus nombres e imaginarnos su historia futura, pero ver también videos de policías y ejército cuando "retomaron el control" del Palacio, ver sus fotos y compararlas, ver sus ojos buscando justicia. Después de esto, estudiar también el proceso jurídico reciente a algunos militares, para que estos jóvenes se den cuenta que nacieron en un país de (hijijteputas) ${ }^{4}$ impunidad, que hay que hacer algo para cambiarlo, pero que ese algo no puede permitir más sangre, más desaparecidos y más datos para una clase futura de la violencia en Colombia. (Escrito de estudiante de primer semestre)

\section{Relato 2:}

La historia colombiana en las últimas décadas se ha caracterizado por forjar en el país un movimiento neoliberal, opresor y desigual que pretende promover en el país un tipo de cultura, economía,

4 Esta palabra fue escrita inicialmente por el estudiante, pero luego procedió a tacharla. Se deja constancia del evento porque el primer intento, tal vez inconsciente, contribuye poderosamente a reforzar el contenido moral del relato. educación y política dirigida a la mercantilización de la sociedad como la conocemos.

Este movimiento hace parte de un proyecto internacional llamado globalización (imperialismo) por parte de Estados con mayor potencia económica.

Colombia de manera obvia durante los últimos gobiernos ha legitimado este movimiento dando la importancia a la lucha de clases, la violencia, la guerra, la falta de oportunidades. El apoyo a la discriminación, el apoyo y el ingreso de otros países para que se lleven los recursos, etc... Formas mediante las cuales el país ha llegado a un nivel en el que su economía está ligada y mantenía por el extranjero, su educación está mercantilizada y articulada al trabajo, su cultura se ha perdido de tal forma que ya casi todos dependemos de modas, y su política reprime al pueblo para no hacer nada en contra. (Relato estudiante de primer semestre)

Relato 3:

Daría una charla pasando rápidamente por los períodos transcurridos desde la conquista puesto que todo está ligado, y para mostrar la historia actual debería hacer un recorrido por la historia misma del país. Haría énfasis en cómo todo eso tiene participación en los problemas que hoy la aquejan.

Les diría a los estudiantes lo siguiente: Desde la conquista hemos estado inmersos en un conflicto interno, esto ha conllevado a pérdidas humanas moralmente desgarradoras para los habitantes. A finales de 1800 y a principios del 1900 se estuvo inmerso en el mayor conflicto dejando miles de muertos. También ha habido buenos personajes pero tristemente fueron eliminados por las mafias políticas del país y es hasta hoy que poco a poco se está levantando una nueva era de oposición al estado que tanto a ustedes como a nosotros nos ha tocado aguantarles las decisiones que afectan negativamente su niñez. Ustedes hoy empiezan una formación que poco a poco les educará sobre estas problemáticas ayudándoles a desarrollar un pensamiento que les permita proponer ideas de cambio. 
El tono moral de estos relatos es notorio en varios sentidos. Primero, por el matiz trágico de las versiones escolares manifiestas, que dejan un "sin salida" frente a los acontecimientos, y que, por tanto, inscriben su sentido en una estela predeterminada a la desgracia. Estos fragmentos expresan más un sentimiento muy subjetivo sobre lo sucedido que una preocupación por mostrar rigor analítico en la descripción de unos acontecimientos. Segundo, subsisten leyendas de buenos o malos, unos personajes nefastos que han marcado la historia, sujetos sin identidad que han empujado el país al abismo, $y$, por otro lado, personajes desvalidos que han sido objeto de infamias ciegas orquestadas por otros. Aquí no hay responsables, ni análisis detallados, sino lecturas maniqueas en las que sobresalen los eventos cobijados por la desgracia que supuestamente caracteriza Colombia.

Según Ruiz (2011), algunas investigaciones demuestran que las versiones escolares sobre la historia suelen combinar de manera dinámica elementos morales e ideológicos, y en esta imbricación los contenidos y los hechos narrados son sacrificados en una saga que acomoda lo sucedido en función de darle peso a la orientación valorativa que se quiere transmitir. Esta aseveración coincide con los fragmentos de testimonios de los estudiantes colombianos atrás presentados. En otras palabras, las opciones éticas o morales pueden determinar el contenido de los conocimientos a legitimar. Los eventos, cuidadosa o arbitrariamente seleccionados, fungen, según la producción de los estudiantes, como mojones o episodios paradigmáticos de una historia delineada con claridad. Más allá del tono infausto que se imprime, no hay opacidades, ni dudas, ni puntos inconclusos, ni fuentes confrontadas o elementos susceptibles de reflexión. La versión es tan desdichada como clausurante.

La invitación a "llenarse de indignación", el "ponerse la piel de gallina", junto a "la enfermedad de las fuerzas armadas", "Locombia" o la palabra tachada (hijueputas) son términos que resaltan por su acento emotivo y que transmiten un determinado tipo de conmoción respecto a lo que ha pasado. Los hechos contados casi que se vuelven secundarios ante un propósito superior: demostrar que siempre ha habido desastre, aflicción. Frente a la fuerza de las expresiones morales, los datos que se mencionan se subordinan a un sentido teleológico: tragedia, violencia, locura... Por otra parte, enunciados que intentaron ubicar algunos culpables en los dramas de la nación, como "las mafias políticas del país" o "la política que reprime al pueblo", terminaron por aportar su ingrediente en la construcción de esa leyenda que señala en unos anónimos actores la culpa de unos males mayores, a la vez que contribuyeron a establecer generalizaciones y a no señalar responsabilidades particulares.

Aunque es claro que no son posibles lecturas del mundo sin pretensiones éticas, ya que el componente moral no puede aislarse de la persona en cuanto que hace parte de la configuración subjetiva (Taylor, 2004), y que, por tanto, es consustancial a las lecturas que el ser humano edifica del mundo, el aprendizaje moral también hace parte de las rutinas escolares, aunque no siempre se explicite su enseñanza ni se tomen los recursos pertinentes para su formación en la escuela. Por ello, parece pertinente proponer, al lado de una comprensión del conflictivo pasado reciente de la nación, una formación ética y moral, posible de realizar en la escuela, que no solo active aproximaciones más abiertas y menos dicotómicas al mundo, sino que permita acercamientos menos prejuiciados a los hechos traumáticos y sensibles de la historia.

\section{Cierre}

Carnovale y Larramendy (2010), evocando a Vezzetti, al proponer alternativas para la enseñanza de la historia reciente, afirman que en el cruce entre memoria e historia existen dos condiciones susceptibles de destacar. La primera es una dimensión intelectual, preocupada por evidenciar los aspectos sobre el conocimiento de pasados traumáticos y jalonado por preguntas como ¿por qué lo que pasó fue así y no de otro modo?, o ¿qué contexto hizo que ello fuera admisible? La segunda es una dimensión ética, que vuelca estos interrogantes sobre la propia 
sociedad, las personas y los grupos involucrados. En términos educativos, esta última dimensión se centra en tratar los valores, las ideas y los presupuestos que motivaban a las personas de aquel pasado, y en generar una discusión sobre las implicaciones de sus esquemas morales para la sociedad de su época y para la actual. Si la primera dimensión está por ser profundizada en la escuela colombiana, la segunda, como se ha visto, lo requiere aún más.

La enseñanza de la historia reciente es un campo estratégico de disputa y objeto de tensión social, pues ella materializa una vieja lucha por establecer los contenidos legítimos de negociar en la escuela (Cuesta, 2002). Colombia, no solo no ha estado ajena de tal dinámica, sino que este tipo de enseñanza ha circulado por espacios sociales propios de la sociedad civil organizada, casi siempre, desligados de la dinámica escolar. De cualquier manera, el contenido y la orientación de la enseñanza de la historia reciente parece en buena parte condicionado por los marcos de referencia éticos y morales que por$\tan$ los sujetos. Es evidente que las opciones morales acomodan los acontecimientos que se recaban del pasado reciente, y esto es determinante, en el caso de la escuela, porque este filtro define no solo el qué enseñar, sino el para qué.

La enseñanza de la historia reciente en Colombia también cuenta con obstáculos de otra naturaleza: dosis fragmentadas y descontextualizadas de libros de texto, preocupados por embutir décadas enteras en la simpleza de unos pocos párrafos que desconocen la complejidad de los procesos. La lógica de las editoriales siempre chocará con la exigencia de comprensión histórica, que requiere amplitud, densidad y apertura, aspectos demasiado caros para el mercado editorial. Hecho que deja intactos o refuerza los prejuicios morales. Adicionalmente, como no se aprende solo de la escuela, y dada la importancia mediática de algunos eventos traumáticos del pasado reciente, la mayoría de colombianos -incluidos los escolares- asisten a versiones caricaturescas de la historia reciente, cuyas narrativas están cargadas de moralismos y personalismos que también riñen con el análisis histórico y que imposi- bilitan miradas menos maniqueas sobre la violencia. Para muchos, la violencia política es un show que se exhibe en pintorescas películas o exitosas telenovelas en las que buenos y malos hacen de las suyas.

De acuerdo con los relatos presentados, estudiantes universitarios de primer semestre reforzaron la tesis que condiciona el aprendizaje escolar de la historia reciente a decisiones morales. Es muy probable que la formación moral de la que fueron objeto los jóvenes estudiantes de la investigación provenga de su educación básica, lógicamente anterior a la experiencia universitaria, pero también de otras instancias de socialización. Así que, tales esquemas morales, pese a ser casi siempre inconscientes y no deliberados, son también aprendidos y obedecen a delicados procesos de formación social y escolar, por tanto, pueden también ser objeto de intervención, interacción y discusión pedagógica.

El actual sesgo moral de las inclinaciones pedagógicas sobre la enseñanza de la historia reciente parece que recoge, aunque transformado, el legado que ha cargado históricamente la enseñanza de este saber en Colombia, en cuanto que durante varias décadas la función de la enseñanza de las ciencias sociales, además de nombres de ríos y de capitales, consistió en insuflar en los escolares un ciudadano virtuoso, obediente, higiénico, católico y patriota (Herrera, Pinilla y Suaza, 2003). Tal misión redentora es ahora demarcada en la exigencia para que los docentes de esta área sean modelo y ejemplo de la salvación de la nación, la resolución de los conflictos y la consecución de la paz y la justicia, tal como se puede inferir en la frase del epígrafe. En palabras de Castillo (2002), la sociedad actual le endilga a la enseñanza de las ciencias sociales la responsabilidad de asumir la solución a profundas problemáticas sociales, por ello, según la autora, "es necesario que los maestros se sustraigan a los mitos que pesan sobre sus hombros" (p. 111).

Ante la imposibilidad de desprenderse de tales mitos, pintados en blanco y negro, quizá sea hora de hacer propuestas para aligerar las cargas, es decir, proponer a los maestros de ciencias sociales e historia negarse a enseñar un mundo de vencedores y 
vencidos. Acompañar la comprensión histórica del pasado reciente con una educación moral que interpele el presente, así como la configuración subjetiva de los estudiantes y sus experiencias biográficas. Además, afirmar que la dimensión ética y moral de la enseñanza no depende de un área en particular del conocimiento, pues los docentes de otras asignaturas pueden contribuir a configurar en la escuela sujetos que en su presente apuesten por resolver los conflictos con argumentos, cuestionar las verdades oficiales, resistir el ser masa y desear modos alternativos de vida buena.

\section{Referencias}

Aponte, J. (2012). Rutas epistémicas y pedagógicas de la primera violencia en la enseñanza de las ciencias sociales: entre la memoria oficial y otras memorias. Revista Colombiana de Educación, 62, pp. 153-164.

Arias, D. (2005). Enseñanza y aprendizaje de las ciencias sociales. Una propuesta didáctica. Bogotá: Cooperativa Editorial Magisterio.

Arias, D. (2014). Identificación con la nación propia en jóvenes universitarios, maestros en formación. Imaginarios sociales de nación y escuela (Tesis doctoral). Universidad Pedagógica Nacional, Bogotá.

Arias, D., y Ruiz, A. (2013). Jóvenes, política e identidad nacional. Un estudio con jóvenes universitarios colombianos. Revista Argentina de Estudios de Juventud, 7, pp. 1-22.

Bauman, Z. (2001). La sociedad individualizada. Madrid: Cátedra.

Carretero, M. (2005). Construir y enseñar las ciencias sociales y la historia. Buenos Aires: Aique.

Carretero, M., y Borrelli, M. (2010). La enseñanza de la historia reciente en la escuela: propuestas para pensar históricamente. En M. Carretero y J. Castorina, La construcción del conocimiento histórico. Enseñanza, narración e identidades (pp. 101-130). Buenos Aires: Paidós.

Carnovale, V., y Larramendy, A (2010). Enseñar la historia reciente en la escuela: problemas y aportes para su abordaje. En I. Siede, Ciencias sociales en la escuela. Criterios para la enseñanza (pp. 237-265). Buenos Aires: Aique.

Castillo, E. (2002). Restos y dilemas profesionales. En E. Castillo et al., Los maestros de ciencias sociales.
Historia escolar y procesos de socialización profesional (pp. 109-128). Bogotá: Cooperativa Editorial Magisterio.

Cuesta, R. (2002). La historia como disciplina escolar: génesis y metamorfosis del conocimiento histórico en las aulas. En C. Focradell e I. Peiró (Coords.), Lecturas de la historia: nueve reflexiones sobre historia de la historiografía (pp. 221-252). Zaragoza: Institución Fernando el Católico.

De Amézola, G. (2008). Esquizohistoria. La Historia que se enseña en la escuela, la que preocupa a los historiadores y una renovación posible de la historia escolar. Buenos Aires: Libros del Zorzal.

Dussel, I. (2002). La educación y la memoria. Notas sobre la política de la transmisión. Revista Anclajes, 6, pp. 267-293.

Falaize, B. (2010). El método para el análisis de los temas sensibles de la historia. En R. Ávila, P. Rivero y P. Domínguez (Coords.), Metodología de investigación en Didáctica de las Ciencias Sociales (pp. 187-205). Zaragoza: Institución Fernando El Católico.

Fazio, H. (2007). La historia del tiempo presente y la modernidad mundo. Historia Crítica, 34, pp. 184-207.

Franco, M., y Levín, F. (2007). El pasado cercano en clave historiográfica. En M. Franco y F. Levín (Comp.), Historia reciente. Perspectivas y desafíos para un campo en construcción (pp. 31-65). Buenos Aires: Paidós.

Funes, P. (2006). Salvar la nación. Intelectuales, cultura y política en los años veinte latinoamericanos. Buenos Aires: Prometeo.

García, L. (2002). Identidad personal y social en el maestro de ciencias sociales. En E. Castillo et al., Los maestros de ciencias sociales. Historia escolar y procesos de socialización profesional (pp. 41-51). Bogotá: Cooperativa Editorial Magisterio.

Giroux, H. (2001). Cultura, política y práctica educativa. Barcelona: Graó.

Grupo Memoria Histórica (2013). ;Basta ya! Colombia: memorias de guerra y dignidad. Bogotá: Imprenta Nacional.

Herrera, M. (2009). Acercamientos a una historia sociocultural del tiempo presente: la estructuración de un campo problemático. Revista Ignis, 2, pp. 12-23.

Herrera, M., y Merchán, J. (2012). Pedagogía de la memoria y enseñanza de la historia reciente. En R. García, 
Jiménez, A. y J. Wilches, Las víctimas, ente la memoria y el olvido (pp. 137-156). Bogotá: Universidad Distrital Francisco José de Caldas.

Herrera, M., Ortega, P., Cristancho, G., y Olaya, V. (2013). Memoria y formación: configuraciones de la subjetividad en ecologías violentas. Bogotá: Universidad Pedagógica Nacional.

Herrera, M., Pinilla, A., y Suaza, L. (2003). La identidad nacional en los textos de ciencias sociales. Colombia 1900-1950. Bogotá: Universidad Pedagógica Nacional.

Higuera, D. (2012). La escuela ante la transmisión del pasado reciente argentino: sentidos comunes, dilemas de la representación y los desafíos del presente. Buenos Aires: Libros libres, Flacso.

Hobsbawm, E. (1983). Introducción: La invención de la tradición. En E. Hobsbawm y T. Ranger (Eds.), La invención de la tradición (pp. 7-21). Barcelona: Crítica.

Huyssen, A. (2002). En busca del futuro perdido. Cultura y memoria en tiempos de globalización. México: Fondo de Cultura Económica.

Jelin, E. (2003). Memorias y luchas políticas. En C. Degregori (Ed.), Jamás tan cerca arremetió lo lejos. Memoria y violencia política en el Perú (pp. 27-48). Lima: Instituto de Estudios Peruanos.

Jelin, E., y Lorenz, G. (Comps.) (2004). Educación y memoria. La escuela elabora el pasado. Madrid: Siglo XXI.

Kriger, M. (2011). La enseñanza de la historia reciente como herramienta clave de la educación política. Narrativas escolares y memorias sociales del pasado dictatorial argentino en las representaciones de jóvenes estudiantes de la Ciudad de Buenos Aires y conurbano (2010-2011). Persona y Sociedad, 3, pp. 29-52.
Lechner, N. (2002). Las sobras del mañana. La dimensión subjetiva de la política. Santiago de Chile: Lom.

Levín, F. (2007). El pasado reciente en la escuela, entre los dilemas de la historia y la memoria. En G. Schujman e I. Siede (Ed.), Ciudadanía para armar. Aportes para la formación ética y política (pp. 157-178). Buenos Aires: Aique.

Mackenzie, E. (2014). Curiosidades de la "Comisión Histórica”. Disponible en: http://www.lahoradelaverdad.com.co/opinion/curiosidades-de-la-comisionhistorica.html (Consultado: 10-10-2014).

Martín-Barbero, J. (2002). Colombia: ausencia de relato $y$ desubicación de lo nacional. Bogotá: Ministerio de Cultura.

Pagés, J., y Santisteban, A. (Eds.) (2013). Una mirada al pasado y al proyecto de futuro. Investigación e innovación en didáctica de las ciencias sociales. España: Universidad Autónoma de Barcelona, Asociación Universitaria de Profesorado de Didáctica de las Ciencias Sociales.

Rodríguez, S. (2012). Formación de maestros para el presente: memoria y enseñanza de la historia reciente. Revista Colombiana de Educación, 62, pp. 165-188.

Ruiz, A. (2011). Nación, moral y narración: Imaginarios sociales en la enseñanza y el aprendizaje de la historia. Buenos Aires: Miño y Dávila.

Saldarriaga, O. (2003). El oficio de maestro. Prácticas y teorías de la pedagogía moderna en Colombia. Bogotá: Cooperativa Editorial Magisterio.

Taylor, Ch. (1989). Las fuentes del yo. La construcción de la identidad moderna. Barcelona: Paidós.

Taylor, Ch. (2004). Imaginarios sociales modernos. Barcelona: Paidós.

Traverso, E. (2007). El pasado. Instrucciones de uso. Madrid: Parcial Pons. 